\title{
Diacidene, a Polyene Dicarboxylic Acid from a Micromonospora Isolate from the German Wadden Sea
}

Birgit Ohlendorf, Dirk Schulz, Pascal Beese, Arlette Erhard, Rolf Schmaljohann, and Johannes F. Imhoff*

Kieler Wirkstoff-Zentrum (KiWiZ) at the Helmholtz Centre for Ocean Research

(GEOMAR), Am Kiel-Kanal 44, D-24106 Kiel, Germany. Fax: +49-431-6004452.

E-mail: jimhoff@geomar.de

* Author for correspondence and reprint requests

Z. Naturforsch. 67c, 445-450 (2012); received November 3, 2011/April 4, 2012

Micromonospora sp. strain DB620 was isolated from a Wadden Sea sediment sample collected near Büsum (Germany) and is closely related (99\% 16S-rRNA gene sequence similarity) to Micromonospora coxensis strain MTCC8093. It produced a new polyene dicarboxylic acid named diacidene (1) and in addition a derivative of chorismic acid, the known 3-[(1-carboxyvinyl)oxy]benzoic acid. The structure elucidation of $\mathbf{1}$ was achieved by applying different 1D and 2D NMR techniques as well as mass spectrometry and UV spectroscopy.

Key words: Micromonospora, Dicarboxylic Acid, Diacidene

\section{Introduction}

Actinomycetes as producers of secondary metabolites remain to be important, even after many decades of active research. Over the years, natural product research focussing on the genus Streptomyces has provided some of the most effective and well established antibiotics, such as erythromycin and tetracycline. Among the actinomycetes, the genus Streptomyces is responsible for the major part of described structures (Bérdy, 2005). However, other genera like Micromonospora and Nocardia are catching up (Bérdy, 2005), and the marine Salinispora tropica CNB-392 (Micromonosporaceae) is the protagonist in one of the recent success stories in natural product research. It is the producer of the proteasome inhibitor salinosporamide which advanced to clinical trials in absolute record time (Fenical et al., 2009). Thus, the current status of natural product research strongly supports further investigations on secondary metabolites of actinomycetes.

Marine sediments have proven a profitable habitat for the isolation of high numbers of Micromonosporaceae (Bredholt et al., 2008; Maldonado et al., 2008; Prieto-Davó et al., 2008). Our isolate, Micromonospora strain DB620, originated from the German Wadden Sea, a unique ecosystem characterized by large areas of tidal flats. In the course of our screening for natural products, this strain was found to produce diacidene (1), a new polyene dicarboxylic acid (Fig. 1).

\section{Results and Discussion}

The substrate mycelium of the strain DB620 had an orange colour. Neither an aerial mycelium nor a soluble pigment was produced. These features fit in well with the description of Micromonospora coxensis (MTCC8093) (Ara and Kudo, 2007) to which DB620 showed the highest similarity in a 16S-rRNA gene sequence analysis (99\%). The genus Micromonospora is characterized by and named after the production of single, small spores which are borne on sporophores branched from substrate hyphae. More specifically, the spores of $M$. coxensis are described to be small, with a dia-

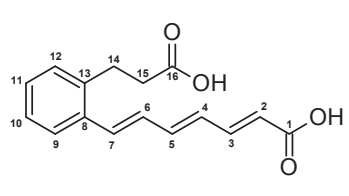

Diacidene (1)

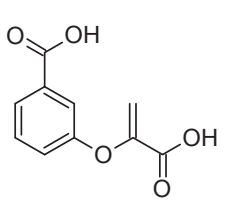

3-[(1-Carboxyvinyl)oxy]benzoic acid
Fig. 1. Chemical structures of diacidene (1) and 3-[(1-carboxyvinyl)oxy]benzoic acid. 
meter in the range between 0.5 and $0.8 \mu \mathrm{m}$, and a nodular to warty surface (Ara and Kudo, 2007). These characteristics are congruent with those of strain DB620, too (Fig. 2).

In the chemical screening, DB620 stood out because of the production of a compound with a molecular mass of $272 \mathrm{~g} / \mathrm{mol}$, which could not be identified by a database research (Antimarin, Dictionary of Natural Products) (Buckingham, 2010; Blunt et al., 2006). Scaling up and isolation of the produced metabolites enabled us to characterize two compounds. We identified the known compound 3-[(1-carboxyvinyl)oxy]benzoic acid (Fig. 1), a derivative of chorismic acid, by ${ }^{1} \mathrm{H}$ NMR and UV data which corresponded well to those described in the literature (Mattia and Ganem, 1994; Ife et al., 1976). The second compound was found to be new, and the structure elucidation showed the molecule to consist of a phenyl ring, a polyene chain, and two carboxylic acid substructures. Hence we named it "diacidene" (1).

The molecular formula $\mathrm{C}_{16} \mathrm{H}_{16} \mathrm{O}_{4}$ was determined by high-resolution mass spectrometry (HRESIMS):273.1136 [M+H] $]^{+}$measured, 273.1121 calculated for $\mathrm{C}_{16} \mathrm{H}_{17} \mathrm{O}_{4}$. The strong absorbance with UV maxima at 205, 243, and $336 \mathrm{~nm}$ already indicated the presence of an extended $\pi$-electron system and was in good accordance with a benzene ring conjugated with three double bonds. The structure of $\mathbf{1}$ was elucidated by analysis of $1 \mathrm{D}\left({ }^{1} \mathrm{H},{ }^{13} \mathrm{C}\right.$ and DEPT) and 2D NMR (HSQC, COSY and HMBC) spectra (Table I, Fig. 3). Some structural features could already be deduced from

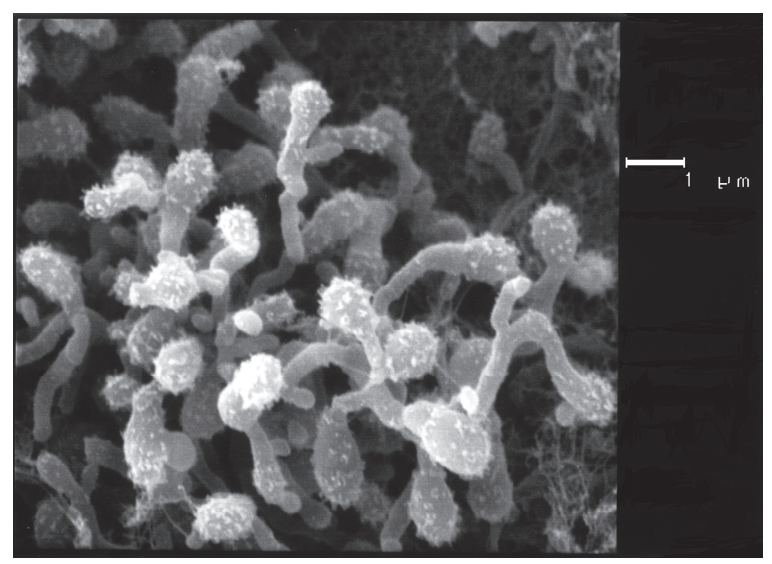

Fig. 2. Scanning electron microscopic photograph of $M i$ cromonospora strain DB620. the ${ }^{1} \mathrm{H}$ NMR spectrum, which clearly showed the presence of two neighbouring methylene groups, $\mathrm{CH}_{2}-14\left(\delta_{\mathrm{C}} 29.4 \mathrm{ppm}, \delta_{\mathrm{H}} 3.03 \mathrm{ppm}\right)$ and $\mathrm{CH}_{2}-15$ $\left(\delta_{\mathrm{C}} 36.4 \mathrm{ppm}, \delta_{\mathrm{H}} 2.52 \mathrm{ppm}\right)$, whose coupling became evident from the respective signal splitting patterns and the coupling constant. No further methylene group, no methyl group, and no $\mathrm{sp}^{3}$-hybridized methine group were detected. All signals, apart from the two mentioned methylene groups, belonged to aromatic and olefinic protons. The signals of the ${ }^{13} \mathrm{C}$ NMR spectrum were in good accordance with the molecular formula and the information obtained from the ${ }^{1} \mathrm{H}$ NMR spectrum. Consistently, the ${ }^{13} \mathrm{C}$ NMR spectrum displayed 16 distinct carbon signals including two belonging to aliphatic methylene groups (C-14 and C-15), two carbonyl carbon atoms $\left(\mathrm{C}-1, \delta_{\mathrm{C}} 170.6 \mathrm{ppm}\right.$, and $\left.\mathrm{C}-16, \delta_{\mathrm{C}} 176.5 \mathrm{ppm}\right)$, and twelve olefinic carbon atoms $\left(\mathrm{C}-2, \delta_{\mathrm{C}} 122.0 \mathrm{ppm}\right.$, to $\left.\mathrm{C}-13, \delta_{\mathrm{C}} 140.1 \mathrm{ppm}\right)$, two of which were quaternary $\left(\mathrm{C}-8, \delta_{\mathrm{C}} 136.5 \mathrm{ppm}\right.$, and $\left.\mathrm{C}-13, \delta_{\mathrm{C}} 140.1 \mathrm{ppm}\right)$. By the ${ }^{1} \mathrm{H}-{ }^{13} \mathrm{C}$ HSQC spectrum it was possible to assign the proton signals to the signals of their directly bound carbon atoms. On top of that, the ${ }^{1} \mathrm{H}-{ }^{1} \mathrm{H}$ COSY spectrum confirmed the presence of three separated spin systems which could already be deduced from the ${ }^{1} \mathrm{H}$ NMR spectrum. Apart from the one consisting of $\mathrm{CH}_{2}-14$ and $\mathrm{CH}_{2}-15$, there was one spin system which included the four aromatic protons $\mathrm{H}-9\left(\delta_{\mathrm{H}} 7.60 \mathrm{ppm}\right)$ to $\mathrm{H}-12\left(\delta_{\mathrm{H}} 7.22 \mathrm{ppm}\right)$ and one which comprised the olefinic protons $\mathrm{H}-2$ $\left(\delta_{\mathrm{H}} 5.92 \mathrm{ppm}\right)$ to $\mathrm{H}-7\left(\delta_{\mathrm{H}} 7.11 \mathrm{ppm}\right)$. The protons $\mathrm{H}-2$ to H-7 obviously formed three conjugated double bonds, $\Delta^{2,3}, \Delta^{4,5}$, and $\Delta^{6,7}$. The corresponding proton signals showed the expected splitting patterns, and the coupling constants of approximately $15 \mathrm{~Hz}$ proved the three double bonds all to be $E$-configured. The protons belonging to the first double bond $\Delta^{2,3}$ both showed ${ }^{1} \mathrm{H}_{-}{ }^{13} \mathrm{C}$ HMBC correlations to the carbonyl carbon atom C-1 $\left(\delta_{\mathrm{C}}\right.$ $170.6 \mathrm{ppm}$ ) which proved that the chain terminated with a carboxy group. H-7 on the other side of the olefinic side chain had long range couplings to the aromatic carbon atoms $\mathrm{C}-8\left(\delta_{\mathrm{C}} 136.5 \mathrm{ppm}\right)$, C-9 $\left(\delta_{\mathrm{C}} 126.8 \mathrm{ppm}\right)$, and C-13 ( $\left.\delta_{\mathrm{C}} 140.1 \mathrm{ppm}\right)$, thus giving evidence of the side chain being connected to the aromatic moiety. The phenyl ring was constructed of the carbon atoms C-8 to C-13 including the quaternary carbon atom which connected the olefinic side chain to the ring $(\mathrm{C}-8)$, the aromatic methine groups $\mathrm{CH}-9\left(\delta_{\mathrm{C}} 126.8 \mathrm{ppm}\right)$ to $\mathrm{CH}-12\left(\delta_{\mathrm{C}} 130.8 \mathrm{ppm}\right)$, and a second quaternary 
Table I. NMR spectroscopic data of $\mathbf{1}$ in methanol- $d_{4}(500 \mathrm{MHz})$.

\begin{tabular}{|c|c|c|c|c|}
\hline Position & $\delta_{\mathrm{C}}$ & $\delta_{\mathrm{H}}(J$ in $\mathrm{Hz})$ & COSY & HMBC \\
\hline 1 & $170.6, \mathrm{C}$ & & & \\
\hline 2 & 122.0, $\mathrm{CH}$ & $5.92, \mathrm{~d}(15.3)$ & 3 & 1,4 \\
\hline 3 & $146.4, \mathrm{CH}$ & 7.37, dd $(15.3,11.3)$ & 2,4 & $1,2,4,5$ \\
\hline 4 & 131.6, $\mathrm{CH}$ & 6.55 , dd $(14.0,11.3)$ & 3,5 & $2,3,6$ \\
\hline 5 & $142.6, \mathrm{CH}$ & 6.88, dd $(10.9,14.0)$ & 4,6 & 3,7 \\
\hline 6 & 131.0, $\mathrm{CH}$ & 6.91 , dd $(10.9,14.5)$ & 5,7 & $4,5,8$ \\
\hline 7 & 134.7, $\mathrm{CH}$ & $7.11, \mathrm{~d}(14.5)$ & 6 & $4,5,8,9,13$ \\
\hline 8 & $136.5, \mathrm{C}$ & & & \\
\hline 9 & $126.8, \mathrm{CH}$ & $7.60, \mathrm{~m}$ & $10-12^{\mathrm{a}}$ & $7,11,13$ \\
\hline 10 & $127.9, \mathrm{CH}$ & $7.21, \mathrm{~m}^{\mathrm{a}}$ & $9,11-12^{\mathrm{a}}$ & 8,12 \\
\hline 11 & $129.5, \mathrm{CH}$ & $7.20, \mathrm{~m}^{\mathrm{a}}$ & $9,10^{\mathrm{a}}, 12^{\mathrm{a}}$ & $9,12,13$ \\
\hline 12 & $130.8, \mathrm{CH}$ & $7.22, \mathrm{~m}^{\mathrm{a}}$ & $9,10-11^{\mathrm{a}}$ & $8,10,14$ \\
\hline 13 & $140.1, \mathrm{C}$ & & & \\
\hline 14 & $29.4, \mathrm{CH}_{2}$ & $3.03, \mathrm{t}(7.9)$ & 15 & $8,12,13,15,16$ \\
\hline 15 & $36.4, \mathrm{CH}_{2}$ & $2.52, \mathrm{t}(7.9)$ & 14 & $13,14,16$ \\
\hline 16 & $176.5, \mathrm{C}$ & & & \\
\hline
\end{tabular}

a Signals are overlapping.

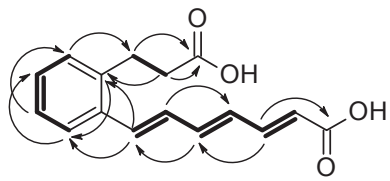

Fig. 3. COSY (bold) and selected HMBC (arrows) correlations important for the structure elucidation of $\mathbf{1}$.

carbon atom $\mathrm{C}-13$ which connected $\mathrm{CH}_{2}-14$ to the ring. The latter connection was confirmed by the ${ }^{1} \mathrm{H}_{-}{ }^{13} \mathrm{C}$ HMBC correlations of $\mathrm{H}_{2}-14$ to $\mathrm{C}-8$, $\mathrm{C}-12$, and C-13. Thus, the ortho substitution of the aromatic ring could be deduced from the longrange couplings from the side chains to the ring and were further supported by the coupling of the aromatic methine groups. Finally, both $\mathrm{H}_{2}-14$ and $\mathrm{H}_{2}-15$ showed ${ }^{1} \mathrm{H}_{-}{ }^{13} \mathrm{C}$ HMBC correlations to the carbonyl carbon atom $\mathrm{C}-16\left(\delta_{\mathrm{C}} 176.5 \mathrm{ppm}\right)$ which proved the second side chain to terminate with a carboxy group, too (Fig. 3). Thus, the structure of the molecule was unequivocally proven.

$\mathbf{1}$ is related to the Streptomycetes metabolites serpentemycins (Wenzel and Bode, 2004) and the monocarboxylic acid derivative serpentene (Ritzau et al., 1993). Serpentene was only weakly antibiotic against Bacillus subtilis, whereas the serpentemycins have been patented due to their strong inhibitory activity in a glycosyltransferase assay (Wink et al., 2004). Due to this information we anticipated diacidene to be active as well, yet no antimicrobial activity could be determined against a selection of bacteria and one yeast (data not shown).

The structure of $\mathbf{1}$ shows some unusual features, specifically the ortho-substituted phenyl ring without an oxygen substituent and the termination of both side chains with carboxy groups. These unusual structural features raise interesting questions concerning the biosynthesis of the compound, questions which have already been addressed for the related serpentene (Ritzau et al., 1993), serpentemycins (Wenzel and Bode, 2004), and pseudorubrenoic acid A (Rickards and Skropeta, 2002). In all cases, there is no doubt that the compounds arise from the acetate metabolism, which has been proven for the serpentemycins by feeding experiments with labelled acetate (Wenzel and Bode, 2004). In analogy to serpentene and the serpentemycins, we propose 1 to be formed by the condensation of eight acetatebuilding blocks, followed by electrocyclization and $\omega$-oxidation (Fig. 4), even though we were not able to detect the monocarboxylic acid in the crude extracts. Rickards and Skropeta (2002) convincingly discussed the probability of an electrocyclization being the key process in the formation of the aromatic ring in pseudorubrenoic acid A. The authors argued that the absence of an oxygen functionality on or adjacent to the aromatic ring suggests a reaction which differs from the normal formation of aromatic rings in polyketide biosyn- 


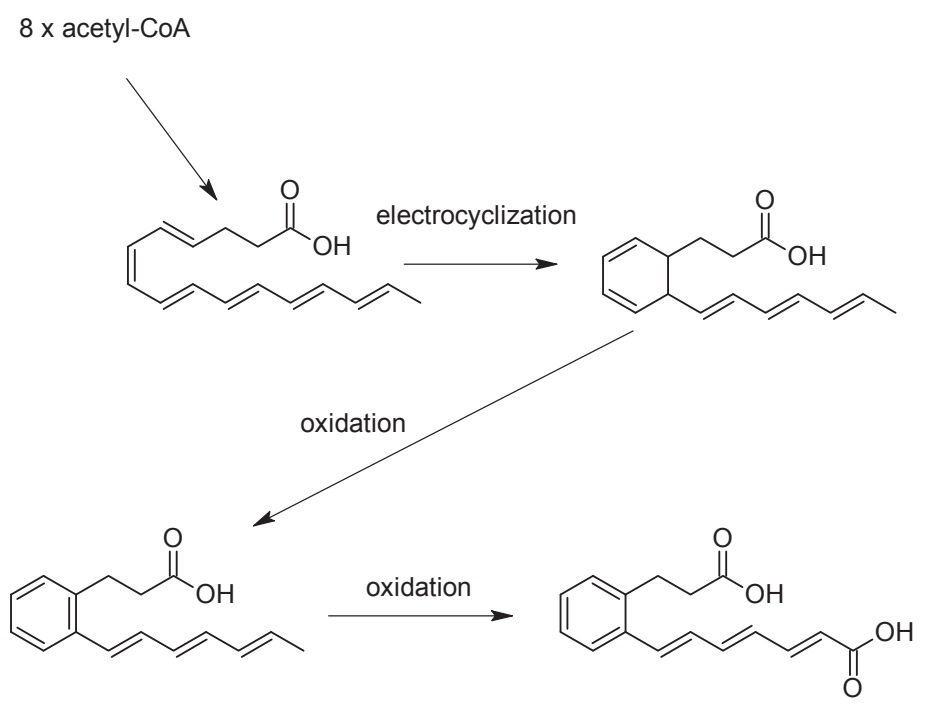

Fig. 4. Proposed biosynthesis of $\mathbf{1}$.

thesis that involves an aldol condensation. All in all, the authors' argumentation leading to the postulation of the presence of an electrocyclase enzyme is compelling, and we suggest a similar reaction in the biosynthesis of $\mathbf{1}$. However, proof of the existence of such an enzyme is still missing.

\section{Experimental}

\section{General experimental procedures}

The optical rotation was measured on a Perkin Elmer (Rodgau, Germany) model 241 polarimeter. UV spectra were obtained on a NanoVue (GE Healthcare, Freiburg, Germany) spectrometer. NMR spectra were recorded on a Bruker (Karlsruhe, Germany) DRX500 spectrometer (500 and $125 \mathrm{MHz}$ for ${ }^{1} \mathrm{H}$ and ${ }^{13} \mathrm{C} \mathrm{NMR}$, respectively), using the signals of the residual solvent protons and the solvent carbon atoms as internal references $\left(\delta_{\mathrm{H}} 3.31 \mathrm{ppm}\right.$ and $\delta_{\mathrm{C}} 49.0 \mathrm{ppm}$ for methanol- $\left.d_{4}\right)$. High-resolution mass spectra were acquired on a benchtop time-of-flight spectrometer (MicrOTOF-II; Bruker Daltonics, Bremen, Germany) with positive electrospray ionization. Analytical reversed phase HPLC-UV/MS experiments were performed using an Onyx Monolithic $\mathrm{C}_{18}$ column $(100 \times 3.00 \mathrm{~mm})($ Phenomenex, Aschaffenburg, Germany) applying an $\mathrm{H}_{2} \mathrm{O}$ (A)/ $\mathrm{MeCN}$ (B) gradient with $0.1 \% \mathrm{HCOOH}$ added to both solvents (gradient: 0 min 5\% B, 4 min $60 \%$ B, 6 min $100 \%$ B; flow $2 \mathrm{~mL} / \mathrm{min}$ ) on a Merck
Hitachi Elite LaChrom system (Darmstadt, Germany) coupled to an ESI-ion trap detector (Esquire 4000; Bruker Daltonics).

Preparative HPLC was carried out using either a LaPrep HPLC system with a P110 pump, a P311 UV detector, a Labocol vario-200 fraction collector (Labomatic Instruments, Allschwil, Switzerland), a Smartline 3900 autosampler, and a Phenomenex Gemini-NX 10 m C18 110 A AX $(100 \times 50 \mathrm{~mm})$ column or a Merck Hitachi system consisting of an L-7150 pump, an L-2200 autosampler, an L-2450 diode array detector, and a Phenomenex Gemini C18 110A AXIA (100 x $21.20 \mathrm{~mm}$ ) column.

\section{Organism}

Strain DB620 was isolated from a sediment sample taken at low tide from the German Wadden Sea near Büsum. The sample was taken from the top of the sediment, filled into a sterile 2-mL reaction tube, and processed within $24 \mathrm{~h}$. The sample was dried at $50{ }^{\circ} \mathrm{C}$ prior to isolation of bacteria. The dry soil sample was pre-incubated in yeast extract medium at $50{ }^{\circ} \mathrm{C}$ for $1 \mathrm{~h}$ and then transferred to chitin medium $(20 \mathrm{mg} / \mathrm{L}$ chitin, $10 \mathrm{mg} / \mathrm{L}$ sea salt) supplemented with cycloheximide $(50 \mathrm{mg} / \mathrm{L})$.

For taxonomical characterization, the DNA extraction was performed with the Qiagen (Hilden, Germany) DNeasy ${ }^{\circledR}$ tissue kit. The bacterial cell 
wall was digested with an enzymatic lysis buffer, containing $20 \mathrm{mg} / \mathrm{mL}$ lysozyme (Sigma Life Science, Munich, Germany). For amplification of the 16S-rRNA gene, the universal eubacterial primers 27F and 1492 ${ }^{10}$ (MWG Biotech AG, Ebersberg, Germany) and the DreamTaq ${ }^{\mathrm{TM}}$ Green PCR Master Mix (Fermentas, St. Leon-Rot, Germany) were used. Obtained sequences were compared with sequences in the EMBL nucleotide database available online at the European Bioinformatics Institute homepage using the Basic Local Alignment Search Tool (nucleotide BLAST) and the RDP-II Project homepage.

A well grown agar plate from strain DB620 was prepared by critical point drying and sputter-coated with gold/palladium. Micrographs were made with a Zeiss (Jena, Germany) DSM940 scanning electron microscope.

\section{Cultivation, extraction, and isolation}

For the production of 1, strain DB620 was grown in a medium consisting of $20 \mathrm{~g}$ glucose, $10 \mathrm{~g}$ tryptone from casein (Roth, Karlsruhe, Germany), and $2 \mathrm{~g}$ calcium carbonate per liter deionized water. Fermentations were carried out for $13 \mathrm{~d}$ on a rotary shaker at $120 \mathrm{rpm}$ and $28^{\circ} \mathrm{C}$.

For the isolation of $\mathbf{1}$, a $10-\mathrm{L}$ fermentation was harvested, and the fermentation broth was separated by centrifugation into culture filtrate and mycelium. The filtrate was applied onto an Amberlite XAD-16 column (Sigma-Aldrich, Steinheim, Germany) and eluted with $\mathrm{H}_{2} \mathrm{O} / \mathrm{EtOH}$ (4:6). The eluate containing 1 was concentrated in vacuo, the aqueous residue was acidified with $\mathrm{HCl}$ to $\mathrm{pH} 4$, and extracted with EtOAc. The organic extract was concentrated in vacuo, to give a crude extract of $0.7 \mathrm{~g}$. This extract was fractionated by column chromatography on Sephadex LH-20 (GE Healthcare) $(3 \times 80 \mathrm{~cm}, \mathrm{MeOH})$. Fractions containing 1 were pooled and further purified by preparative RP-HPLC (Phenomenex Gemini C18 110A AXIA, $100 \times 21.20 \mathrm{~mm}$; Phenomenex) with $\mathrm{CH}_{3} \mathrm{CN}$ and $0.1 \% \mathrm{HCOOH}$ as solvents using linear gradient elution from $30 \%$ to $50 \% \mathrm{CH}_{3} \mathrm{CN}$ over $15 \mathrm{~min}$ at a flow rate of $15 \mathrm{~mL} / \mathrm{min}$ and UV detection at $335 \mathrm{~nm}$. This yielded $5 \mathrm{mg}$ of $\mathbf{1}$.

Diacidene (1): Pale yellow, amorphous solid. UV (MeOH): $\lambda_{\max }(\log \varepsilon)=336$ (4.34), 243 (3.93), 205 (4.20) nm. - 1D and 2D NMR: see Table I. HRESIMS: $m / z=273.1136$; calcd. for $[\mathrm{M}+\mathrm{H}]^{+}$ $273.1121\left(\mathrm{C}_{16} \mathrm{H}_{17} \mathrm{O}_{4}\right)$.
3-[(1-Carboxyvinyl)oxy]benzoic acid: Brownish, amorphous solid. - UV (MeOH): $\lambda_{\max }(\log \varepsilon)=$ 288 (3.30), 229 (4.02), 215 (4.04) nm. - ${ }^{1} \mathrm{H}$ NMR $\left(500 \mathrm{MHz}\right.$, methanol- $\left.d_{4}\right): \delta=7.79(1 \mathrm{H}, \mathrm{ddd}, J=$ 7.7, 1.0, $1.7 \mathrm{~Hz}, \mathrm{H}-6), 7.62(1 \mathrm{H}, \mathrm{dd}, J=2.6,1.7 \mathrm{~Hz}$, $\mathrm{H}-2), 7.46(1 \mathrm{H}, \mathrm{dd}, J=7.7,8.4 \mathrm{~Hz}, \mathrm{H}-5), 7.25(1 \mathrm{H}$, ddd, $J=8.4,2.6,1.0 \mathrm{~Hz}, \mathrm{H}-4), 5.84(1 \mathrm{H}, \mathrm{d}, J=$ $2.0 \mathrm{~Hz}, \mathrm{H}-3$ 'a), $5.10(1 \mathrm{H}, \mathrm{d}, J=2.0 \mathrm{~Hz}, \mathrm{H}-3$ 'b). HRESIMS: $m / z=231.0271$; calcd. for $[\mathrm{M}+\mathrm{Na}]^{+}$ $231.0264\left(\mathrm{C}_{10} \mathrm{H}_{8} \mathrm{O}_{5} \mathrm{Na}\right)$.

\section{Antimicrobial assays}

Antimicrobial assays were performed using Bacillus subtilis DSM 347, Staphylococcus lentus DSM 6672, Xanthomonas campestris DSM 2405, and Candida albicans DSM 1386. Overnight cultures of the test organisms in tryptic soy broth were diluted with medium to an optical density (at $600 \mathrm{~nm}$ ) of $0.01-0.05$. The assays were prepared by transferring $2.02 \mu \mathrm{L}$ of a $10 \mathrm{~mm}$ solution (in DMSO) of the test compound and $200 \mu \mathrm{L}$ of cell suspension culture into a well of a 96-well microtiter plate. The microtiter plates were incubated for $5 \mathrm{~h}$ at $37^{\circ} \mathrm{C}$ (B. subtilis, $S$. lentus, and C. albicans) or $14-16 \mathrm{~h}$ at $28{ }^{\circ} \mathrm{C}(X$. campestris) before $10 \mu \mathrm{L}$ of a resazurin solution $(0.2 \mathrm{mg} / \mathrm{mL}$ phosphate-buffered saline) were added to each well; the plates were incubated for another 5-30 min. To evaluate cell viability, the reduction of resazurin to resorufin was assessed by measuring the absorbance at $600 \mathrm{~nm}$ (reference $690 \mathrm{~nm}$ ). The resulting values were compared with a positive $(10 \mu \mathrm{M}$ chloramphenicol for bacteria; $10 \mu \mathrm{m}$ nystatin for the yeast) and a negative (no compound) control, respectively, on the same plate.

\section{Acknowledgements}

The authors gratefully thank G. KohlmeyerYilmaz, M. Höftmann as well as Dr. F. Sönnichsen for running and processing NMR experiments. This study is from the Kieler Wirkstoff-Zentrum (KiWiZ) at GEOMAR which was supported by the Ministry of Science, Economic Affaires and Transport of the State of Schleswig-Holstein (Germany) in the frame of the "Future Program for Economy" co-financed by the European Union (EFRE). 
Ara I. and Kudo T. (2007), Two new species of the genus Micromonospora: Micromonospora chokoriensis sp. nov. and Micromonospora coxensis sp. nov., isolated from sand soil. J. Gen. Appl. Micobiol. 53, 29-37.

Bérdy J. (2005), Bioactive microbial metabolites. J. Antibiot. 58, $1-26$.

Blunt J. W., Munro M. H., and Laatsch H. (2006), Antimarin Database. University of Canterbury, Christchurch, New Zealand.

Bredholt H., Fjaervik E., Johnsen G., and Zotchev S. B. (2008), Actinomycetes from sediments in the Trondheim Fjord, Norway: Diversity and biological activity. Mar. Drugs 6, 12-24.

Buckingham J. (ed.) (2010), Dictionary of Natural Products, Version 19.2. CRC Press, London, UK.

Fenical W., Jensen P. R., Palladino M. A., Lam K. S., Lloyd G. K., and Potts B. C. (2009), Discovery and development of the anticancer agent salinosporamide A (NPI-0052). Bioorg. Med. Chem. 17, 2175-2180.

Ife R. J., Ball L. F., Lowe P., and Haslam E. (1976), The shikimate pathway. Part V. Chorismic acid and chorismate mutase. J. Chem. Soc. Perkin Trans. 1, 1776-1783.

Maldonado L. A., Stach J. E. M., Ward A. C., Bull A. T., and Goodfellow M. (2008), Characterisation of micromonosporae from aquatic environments using molecular taxonomic methods. Antonie van Leeuwenhoek 94, 289-298.

Mattia K. M. and Ganem B. (1994), Is there another common intermediate beyond chorismic acid in the shikimate pathway? Synthesis of trans-3-[(1-carboxyvinyl)oxy]-6-hydroxycyclohexa-1,4-diene-1-carboxylic acid. J. Org. Chem. 59, 720-728.

Prieto-Davó A., Fenical W., and Jensen P. R. (2008), Comparative actinomycete diversity in marine sediments. Aquat. Microb. Ecol. 52, 1-11.

Rickards R. W. and Skropeta D. (2002), Electrocyclic processes in aromatic biosynthesis: a biomimetic study of pseudorubrenoic acid A. Tetrahedron 58, 3793-3800.

Ritzau M., Drautz H., Zähner H., and Zeeck A. (1993), Serpentene, a novel polyene carboxylic acid from Streptomyces. Liebigs Ann. Chem., 433-435.

Wenzel S. C. and Bode H. B. (2004), Novel polyene carboxylic acids from Streptomyces. J. Nat. Prod. 67, $1631-1633$.

Wink J., Kurz M., and Vertesy L. (2004), Polyene carboxylic acid derivatives, method for their production and the use thereof. CA 249075. 